\title{
OS MORADORES DO LIXÃO DE CAMIPINA GRANDE
}

Maria Zélia Pereira Fernandes*

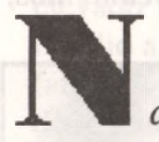

este artigo nos propomos a analisar a moradia e as condições de trabalho dos Catadores de

\section{Lixo de Campina Grande.}

Esta condição de trabalho tem sido também uma das estratégias de sobrevivência utilizada pela população desempregada e sem qualificação profissional do município de Campina Grande no Estado da Paraíba, de modo a compreender como essa atividade "permite" sua reprodução social e de sua família.

Para entendermos essa estratégia, resgatamos todo o processo de produção na catação de lixo. Analisamos a construção do espaço social, onde se articulam produção e moradia; as condições de trabalho; a comercialização do lixo e as condições de vida desses trabalhadores - nível de renda, moradia, padrão alimentar, saúde e educação. Para tanto, utilizamo-nos de uma pesquisa tipo participativa, na qual foram aplicados questionários e entrevistados 50 chefes de família, no período de fevereiro a junho de 1990.

Este espaço que está sendo produzido e (re)produzido pelos Catadores de Lixo é palco privilegiado onde se processa a mais explícita forma de miséria, onde o homem para sobreviver precisa travar disputa com animais como: vacas, cachorros, porcos e insetos-baratas, ratos e moscas. A pobreza visível nessa paisagem testemunha a condição de vida do homem que é desprovido dos meios de produção.

\section{PERFIL DAS FAMÍLIAS CATADORAS DE LIXO}

Trabalhamos com 50 famílias num total de 265 pessoas, sendo 149 homens e 116 mulheres. Desse número $60 \%$ moram no próprio lixão articulando produção e moradia e $40 \%$ em vários bairros periféricos pobres da cidade. Quanto à origem dessas famílias, $70 \%$ foram expulsas do campo em decorrência da concentração fundiária, da pecuarização, hoje também poupadora de mão-de-obra, e do não cumprimento das obrigações trabalhistas por parte dos latifundiários. "Trabalhei mais de 15 anos na terra dos outros, na hora que o dono quis me jogar na rua, não olhou o quanto eu trabalhei pra ele. Sai pelo mundo afora, morando um dia aqui outro ali, rolando como folha seca com minha família até chegar aqui." (Catador, 48 anos)

Os $30 \%$ restantes argumentam que migraram para a cidade esp o n t a neamente, objetivan do melhorar as condições de vida através do acesso a um emprego. Embora afirmem que migraram espontaneamente, o nível de percepção da rea$\mathrm{li} \mathrm{d} \mathrm{a} \mathrm{d} \mathrm{e}$ dessas famílias não as torna capazes de perceber que se o campo oferecesse todas as condições de sobrevi- vência, não migrariam para a cidade.

"Tinha um pedacinho de terra e fui tentato pelo meu vizinho para vendê-la. Acabei não resistindo e vendi. Partimos para a cidade, aventurar uma vida melhor. Sonhava trabalhar numa fábrica, colocar meus filhos na escola, ter uma casa decente; veja no que deu: nem terra, nem emprego, nem casa. Hoje, para não morrer de fome, vivo nessa situação com minha família." (Catador, 42 anos)

Vale salientar que a grande maioria dessas famílias passou por várias etapas de migração desde o seu local de origem. 
Dentre os catadores de lixo, $31 \%$ são crianças com idade inferior a 12 anos, que já participam do processo produtivo objetivando complementar a renda familiar.

"Quando eu não estou catando ou separando lixo, estou na feira catando frutas $e$ verduras que são jogadas no chão, pra gente comer." (Catador, 10 anos) lixo pra ver se arranjo mais um dinheirinho. Vivo sem saúde, esse trabalho é pesado demais para mim por conta da coluna, quando não aguento mais a dor nas costas me sento um pedaço e depois continuo." (Catador, 70 anos)

A mulher também marca sua presença no forno do lixão, como uma estratégia na obtenção de um melhor ganho. A grande maioria das mães leva
Os $20 \%$ restantes são trabalhadores assalariados (garis, serventes de pedreiro, vigilantes) que têm no lixo uma atividade complementar. Esse procedimento ocorre quando é necessário complementar a renda na tentativa de superar os limites da pobreza. Esta conjugação é uma das estratégias de reprodução da família.

"Aqui ninguém pede documentos,

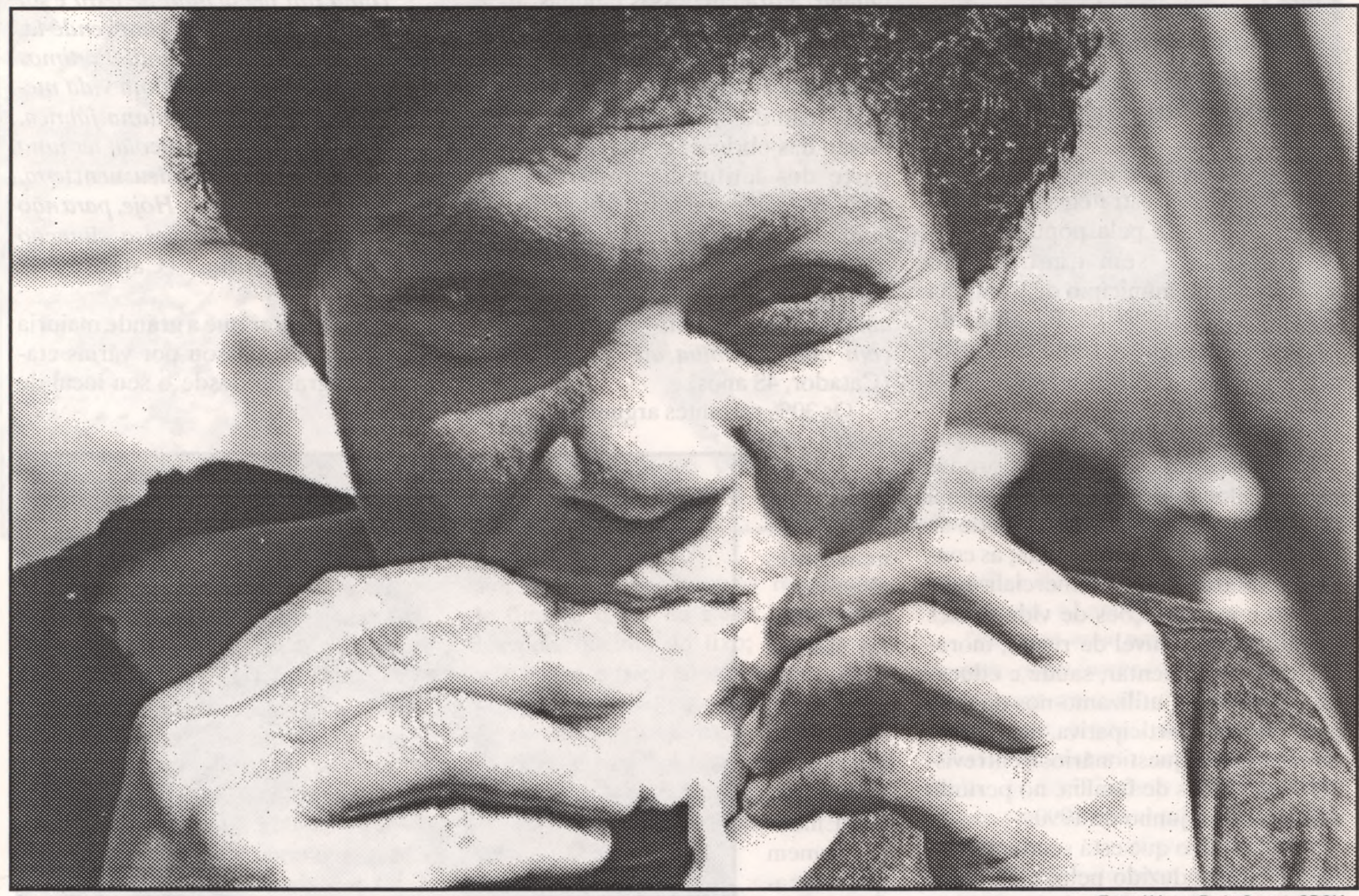

Foto: Alderon P. da Costa - CDCM

Semelhante dado desnuda uma contradição quando comparado com os belíssimos projetos governamentais que são apresentados para solucionar os problemas dos menores.

A presença de idosos com mais de 65 anos é também um fato marcante na catação do lixo. Embora aposentados, continuam lá recolhendo lixo para sobreviver. Isso mostra também o descaso do Estado para com a população inativa.

"O dinheiro que recebo do INSS, não dá nem pra pagar a bodega. Não tenho uma casa para morar, pago aluguel de um quarto, o jeito é me virar no os filhos menores para vigiar o resultado de seu trabalho e também carregar o lixo catado até a porta dos barracos onde vai ser separado para comercialização.

"Fui abandonada pelo meu marido, fiquei com 5 filhos, todos de cobrir com um balaio. Tentei trabalhar em outro serviço melhor, como não tinha onde deixar as crianças, a única saída foi o lixo, porque aqui estamos todos juntos $e$ trabalhando." (Catadora, 28 anos)

Das 50 familias entrevistadas, $80 \%$ trabalham exclusivamente na catação do lixo e afirmam "sustentar" economicamente a familia com esta atividade. nem tem fila de inscrição, é só a gente comprar um "gancho" e entrar na luta. Apesar da miséria do lixo é melhor do que trabalhar ganhando salário mínimo nas fábricas. Aqui não estamos sujeitos a ninguém, não marcamos ponto e trabalhamos na hora que quiser." (Catador, 35 anos)

O catador vê apenas essa vantagem em relação a uma parte do seu trabalho, ou seja, não tem horário fixo, nem patrão para regular a sua vida, no entanto, lhe passa desapercebida a relação de subordinação e exploração a que está sujeito por parte das outras categorias também envolvidas na reci- 
clagem do lixo como: o atravessador que vai comprar o lixo no próprio lixão, o dono das sucatas e a própria fábrica, que compra toda produção de lixo dos catadores. Logo, todos se apropriam do sobretrabalho do catador.

Em relação ao tamanho das famílias observou-se que $50 \%$ delas têm em média de 6 a 7 membros, podendo ser consideradas famílias numerosas. $\mathrm{O}$ elevado número de moradores por domicilio afeta os níveis de vida do grupo familiar, tendo em vista que os custos de manutenção tendem a aumentar à medida que a família cresce. Daí a necessidade de mais participantes na catação de lixo como uma forma de garantir sua reprodução social.

\section{CONDIÇÕES DE TRABALHO DOS CATADORES DE LIXO}

A catação de lixo é uma atividade que exige um grande esforço físico por parte dos catadores. Diariamente, no lixão, são despejados em média 30 caminhões de lixo, com um depósito mensal de 8 mil toneladas incluindo lixo domiciliar, industrial e hospitalar. A medida que o lixo é despejado, todos os catadores partem numa luta desenfreada à procura dos melhores "produtos"; os mais fortes e mais experientes sempre conseguem catar a melhor parte.

Os instrumentos de trabalho são os mais precários possíveis e são confeccionados pelos próprios catadores. Entre eles o mais importante é o "gancho" - trata-se de um pedaço de ferro com dentes bem afiados que serve para remover o lixo.

Dos poderes públicos não recebem a mínima assistência.Catam o lixo da maneira mais rudimentar, não usam luvas, quanto muito, usam sandálias japonesas, alguns utilizam sapatos e, esses são provenientes do lixo, a grande maioria cata lixo com os pés descalços.

"A gente aqui se vira como pode. Se depender da Prefeitura, se morre aqui mesmo. Os políticos só lembra de nós quando quer voto. " (Catador, 38 anos)

A jornada de trabalho varia de 6 a 15 horas diárias. Os que moram no lixão trabalham de domingo-a-domingo; até ao sábado ficam na boca do lixo, e no domingo vão selecionar o material catado. Já os que moram fora do lixão, após a venda da produção retornam para os bairros da periferia. Normalmente, para garantir a reprodução da família trabalham muitas vezes além das condições físicas, tendo em vista que catam lixo noite a dentro, pois o último caminhão chega ao local às 23 horas.

A catação de lixo é uma atividade "invisível" que não aparece nas estatísticas oficiais, porém, é necessária aos setores modernos de produção. A seleção feita pelos catadores dos produtos não orgânicos, serve para reduzir os custos das matérias-primas das indústrias que trabalham com material ferroso, plásticos, papelão, etc. Como essa atividade não é regulamentada, os catadores não têm nenhum vínculo empregatício, não gozam dos benefícios sociais que lhes caberiam por direito.

\section{A MORADIA E CONDIÇÕES DE VIDA DOS QUE VIVEM NO LIXAO}

O lixão, além de local de trabalho, é também local de moradia para a maioria dos catadores. Eles alegam e justificam sua permanência nessa área, por vários motivos: não possuem casa própria; não podem pagar aluguel; querem estar presentes no lixo quando chega cada carro de lixo; poder ocupar lugar privilegiado na hora do despejo; vigiar o resultado da produção tendo em vista que a mesma fica armazenada a céu aberto. Essas várias justificativas são formas de expressar como a instalação da moradia no próprio local de trabalho se explica pelo processo de catação do lixo e pelas dificuldades de acesso à moradia em outros locais da cidade.

Apenas $10 \%$ possuem casa própria, isso mesmo numa das áreas mais distantes do perímetro urbano, numa localidade chamada Catingueira, em terrenos que foram doados ou ocupados. Dentre os catadores, $30 \%$ pagam aluguel em vilas de quartos e cortiços, também localizados em bairros periféricos com precárias condições de infraestrutura. Os $60 \%$ restantes moram no próprio lixão onde é despejado todo lixo coletado na cidade, numa condição subumana em barracos confeccionados de madeira, papelão e sacos de plástico retirados do próprio lixo. Vale salientar que sua reprodução social não é "garantida" apenas pelo dinheiro proveniente da comercialização do lixo, mas da grande parte dos alimentos provenientes do lixo dos supermercados e panificadoras, dos medicamentos e vestuário do lixo domiciliar e hospitalar.

"Nós damos graças a Deus quando chega o lixo dos supermercados. Vem galeto já até mole, vem fruta podre $e$ amassada, mas tudo serve. A mulher prepara a carne com muito limão e dá pra gente traçar. É só quando nós podemos comer uma garra de carne." (Catador, 38 anos)

"Nós comemos de tudo, a gente só quer saber se mata a fome. A barriga da gente não sabe se a comida foi do lixo ou da barraca de D. Maria." (Catador, 15 anos)

Das 50 residências visitadas, constatou-se que: 5 casas são de alvenaria, 10 são de taipa, construídas fora do espaço do lixão e 35 são confeccionadas de papel, papelão, plástico e pedaços de madeira, estas localizadas no próprio terminal do lixão. Quanto à estrutura das moradias, $40 \%$ possuem piso cimentado e $60 \%$ são de chão batido. Geralmente, essas "casas" possuem no máximo dois cômodos, que são insuficientes para acomodar todos os membros da família, que em média são de 6 a 7 pessoas.

Quanto ao saneamento básico, $36 \%$ das casas visitadas possuem água e energia, as que estão fora do lixão e, $64 \%$ não desfrutam desses equipamentos básicos. Verificou-se que uma minoria, apenas tem uma torneira no canto da casa ou do quintal, de onde se retira com latas, a água de beber, cozinhar e tomar banho. Como os catadores que moram no lixão são totalmente desassistidos pelos poderes públicos, após uma série de reivindicações feitas à Prefeitura para que fosse solicitado junto à CAGEPA uma "pena d'água" (termo usado por uma catadora) para resolver o problema da comunidade, como nunca foram atendidos, quebraram um cano que leva água para o Distrito Industrial e de lá retiram água para suas necessidades.

Quanto às instalações sanitárias, essas são precárias. Em $80 \%$ das casas visitadas, os excrementos dos seus ocupantes são despejados em buracos cavados no fundo do quintal ou num 


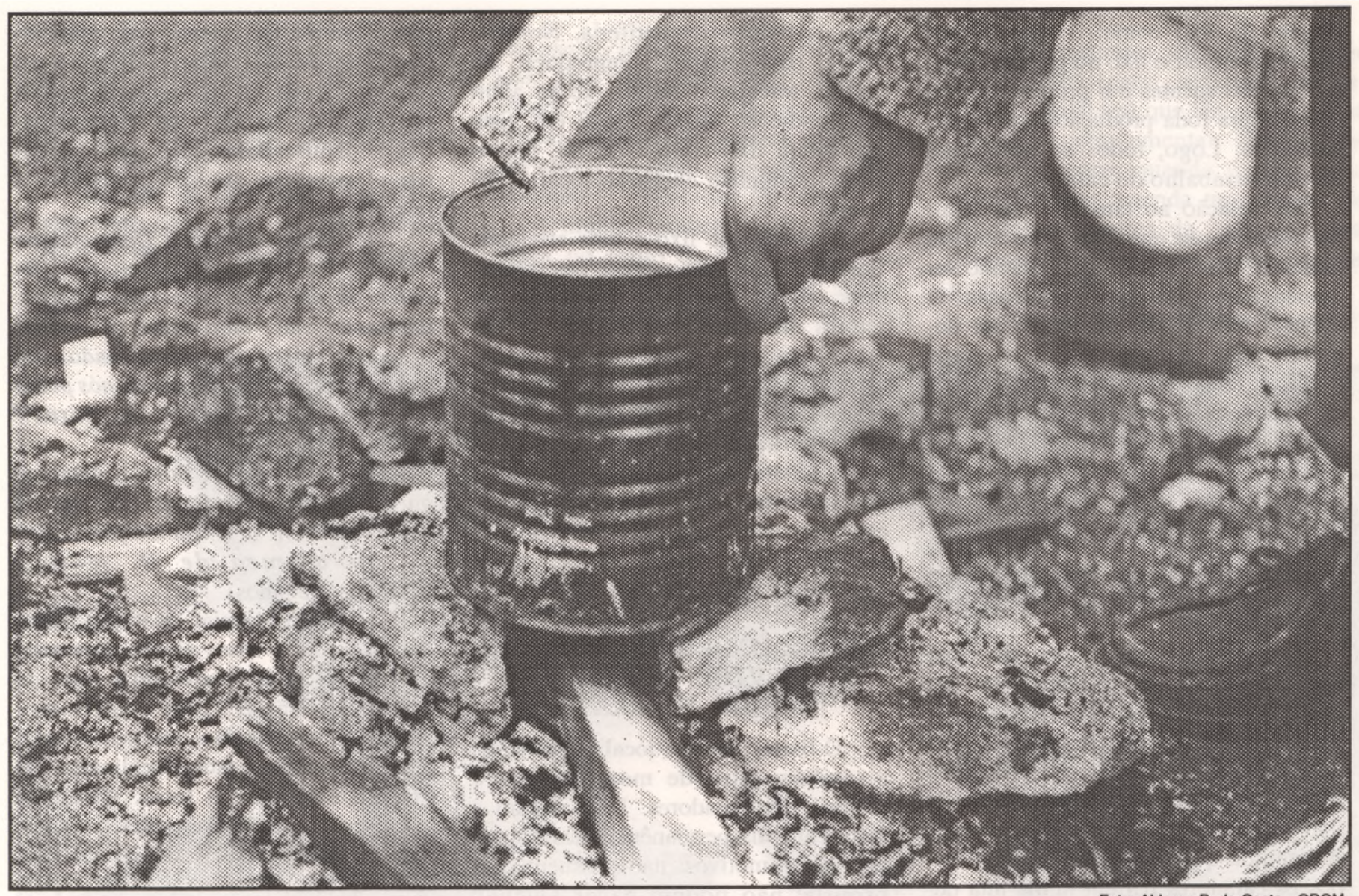

Foto: Alderon P. da Costa - CDCM

"sanitário" improvisado de lata ou de papelão. Apenas $20 \%$ possuem sanitários, os quais em qualidades bem rudimentares, as chamadas latrinas.

Essa caracterização habitacional dos catadores de lixo, reflete na paisagem social a condição de miséria de uma categoria de trabalhadores que reside num espaço de grande utilidade para o capital, onde é comum a convivência de homens, animais e lixo. É necessário investigar e analisar as extorsões que se dão com o rebaixamento das condições de vida dos trabalhadores. Quanto menos da riqueza social for gasto para alimentar, vestir, cuidar da moradia e saúde dos trabalhadores, tanto maior será a parcela que sobrará dessa mesma riqueza e que entrará no circuito da acumulação do capital.

Em relação à questão da saúde no espaço do lixão os catadores são totalmente desassistidos. O lixão se constitui num dos mais importantes pólos irradiadores de insetos e bactérias, já que o lixo fica armazenado a céu aberto. Nessa área há proliferação de vários tipos de doenças. As mais frequentes são: gripes e pneumonias resultantes da fumaça cheia de gases contaminados pela queima do lixo; doenças de pele (sarna e frieiras) verminose e problemas digestivos causados pela ingestão de alimentos do lixão. Outro dado importante ligado a esse aspecto é que o lixo hospitalar altamente contaminado também é depositado no mesmo local.

"Do lixo do hospital eu aproveito todo remédio, roupa usada, pedaços de lençol, travesseiro e colchão. Do plástico do soro faço copos para usar na cozinha." (Catadora, 28 anos)

Como no lixão não existe nenhum serviço de infra-estrutura, quando ocorrem acidentes ou problemas mais sérios de saúde, as pessoas procuram a assistência médica pública como também recorrem à 'medicina popular.

"Quando o problema é muito grave, vamos ao hospital para a emergência, $o$ médico olha pra gente, parece que sente até nojo, manda aplicar uma injeção $e$ passa um remédio. Como a gente não tem dinheiro pra comprar, voltamos aqui pro lixão e metemos a cara nos remédios do mato e nas rezadeiras." (Catadora, 42 anos)

"Eu trato meu povo é com remédio do mato, faço lambedor de saião e hortelã para os que estão com catarro; trato feridas com confrei; dor de barriga $e$ vômito com marcela; sarna e frieira com melão de São Caetano. Vou lá perder tempo com médicos que não liga pra gente!"

(Catadora, 38 anos)

Esses depoimentos retraram com transparência como anda o atendimento médico-hospitalar às categorias que não têm acesso e nem condições de recorrer à medicina privada.

Essa é a realidade da população que vive no lixão, que sofre os efeitos da exploração capitalista e que tem sua reprodução subordinada à forma de como se organiza o espaço. Para esses trabalhadores, o lixo ao invés de ser visto como elemento imprestável, passa a ser fonte de renda e "garantia de sobrevivência".

* Maria Zélia P. Fernandes é Professora e Coordenadora do Curso de Geografia da FELCS - Universidade Estadual da Paraíba 